\title{
Regio-controlled Oxidative Polymerization of 2,5-Dimethylphenol by Using CuCl-TMEDA Complex
}

\author{
Yasuo Suzuki, ${ }^{1}$ Yuji Shibasaki, ${ }^{* 2}$ and Mitsuru Ueda ${ }^{1}$ \\ ${ }^{1}$ Department of Organic and Polymeric Materials, Graduate School of Science and Engineering, \\ Tokyo Institute of Technology, 2-12-1-H120 O-okayama, Meguro-ku, Tokyo 152-8552 \\ ${ }^{2}$ Department of Applied Chemistry, Iwate University, 4-3-5 Ueda, Morioka 020-8551
}

(Received July 18, 2007; CL-070756; E-mail: yshibasa@iwate-u.ac.jp)

A regio-controlled poly(2,5-dimethyl-1,4-phenylene ether) was successfully prepared by the oxidative coupling polymerization of 2,5-dimethylphenol using di- $\mu$-hydroxobis $\left[\left(N, N, N^{\prime}, N^{\prime}\right.\right.$ tetramethylethylenediamine) copper(II)] as a catalyst under oxygen. The catalyst effectively promoted the regio-controlled polymerization even at the concentration of $0.1 \mathrm{~mol} \%$ to the monomer, and the resulting polymer showed a melting temperature at $280{ }^{\circ} \mathrm{C}$.

Oxidative coupling polymerization is a well-known method to prepare various kinds of polymers especially poly(phenylene ether)s (PPE). ${ }^{1}$ Among them, PPE prepared from 2,6-dimethylphenol is widely used as an engineering plastic because of the good insulating and mechanical properties, and thermo-stability. ${ }^{1}$ The polymerization is believed to proceed via radical process, which makes it difficult to polymerize phenol derivatives without substituents on 2 and 6 positions. Several papers have been published to control the coupling regularity of the substituted phenol polymerization. ${ }^{2}$

We very recently reported that a simple catalyst based on $\mathrm{CuCl}-2$-phenylpyridine complex (in situ formation using $\mathrm{CuCl}$ with 100 equiv. of 2-phenylpyridine) promoted the regio-controlled oxidative coupling polymerization of 2,5-dimethylphenol, giving the semicrystalline polymer free from branching units and gel in good yield. ${ }^{3}$ The regio-regularity might attribute to the bulky copper complex, which suppressed the unfavorable branching coupling.

To prevent the unfavorable $\mathrm{C}-\mathrm{C}$ coupling during the polymerization, the excess amounts of pyridine derivatives are generally required. In contrast, aliphatic amines are known to be effective ligands for oxidative coupling polymerization of 2,6-dimethylphenol. Higashimura et al. reported a regio-controlled polymerization of 2,5-dimethylphenol by using a copper complex with bulky tridentate aliphatic amine ligands with the excess amounts of 2,6-dimethylpyridine as an additive. ${ }^{2 \mathrm{~d}}$ Therefore, finding a catalyst that is more accessible and does not need extra additives is important for the development of an economical and environmental method. Here, we report a successful synthesis of regio-controlled poly(2,5-dimethyl-1,4-phenylene ether) by the oxidative coupling polymerization of 2,5-dimethylphenol using di- $\mu$-hydroxobis $\left[\left(N, N, N^{\prime}, N^{\prime}\right.\right.$-tetramethylethylenediamine) copper(II)] (CuCl-TMEDA) complex under mild conditions.

The oxidative coupling polymerization of 2,5-dimethylphenol was carried out with CuCl-TMEDA complex in $o$-dichlorobenzene under oxygen (Scheme 1). The chloroform-soluble polymer with the number-average molecular weight $\left(M_{\mathrm{n}}\right)$ of 8500 and polydispersity index (PDI) of 5.0 is obtained in $65 \%$

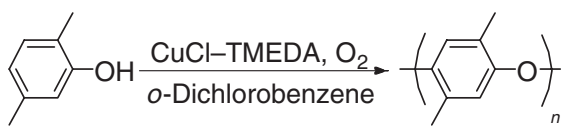

Scheme 1. Oxidative coupling polymerization of 2,5-dimethylphenol.

Table 1. Polymerization of 2,5-dimethylphenol ${ }^{\mathrm{a}}$

\begin{tabular}{|c|c|c|c|c|c|c|}
\hline Run & $\begin{array}{l}\text { Amine } \\
\text { /equiv. }\end{array}$ & $\begin{array}{c}\text { Temp } \\
/{ }^{\circ} \mathrm{C}\end{array}$ & $\begin{array}{c}\text { Time } \\
/ \mathrm{h}\end{array}$ & $\begin{array}{c}\text { Yield }^{\mathrm{b}} \\
/ \%\end{array}$ & $M_{\mathrm{n}}{ }^{\mathrm{c}}$ & $\mathrm{PDI}^{\mathrm{c}}$ \\
\hline 1 & - & 30 & 7 & 65 & 8500 & 5.0 \\
\hline 2 & - & 40 & 0.7 & 70 & 4600 & 3.3 \\
\hline 3 & - & 40 & 1 & (gel) & $-^{\mathrm{d}}$ & $-^{\mathrm{d}}$ \\
\hline 4 & 3 & 40 & 1 & 68 & 5800 & 3.3 \\
\hline 5 & 3 & 40 & 1.5 & (gel) & $-^{\mathrm{d}}$ & $-^{\mathrm{d}}$ \\
\hline 6 & 5 & 40 & 3 & 71 & 6300 & 5.8 \\
\hline 7 & 5 & 40 & 4 & (gel) & $-^{\mathrm{d}}$ & $-^{\mathrm{d}}$ \\
\hline $8^{e}$ & - & 40 & 6 & 65 & $-^{\mathrm{f}}$ & $-^{\mathrm{f}}$ \\
\hline $9^{g}$ & - & 40 & 6 & 29 & $-^{\mathrm{f}}$ & $-^{f}$ \\
\hline
\end{tabular}

${ }^{\mathrm{a} C}$ Conditions; $\mathrm{CuCl} 1 \mathrm{~mol} \%$ in dichlorobenzene under oxygen atmosphere. ${ }^{\mathrm{b}} \mathrm{MeOH}$ insoluble part. ${ }^{\mathrm{c}}$ Determined by GPC $\left(\mathrm{CHCl}_{3}, \mathrm{PSt}\right.$ standard $) .{ }^{\mathrm{d}} \mathrm{Not}$ determined. ${ }^{\mathrm{e}} 0.5 \mathrm{~mol} \% \mathrm{CuCl}$ was used. ${ }^{\mathrm{f}}$ Chloroform insoluble white powders were obtained. ${ }^{\mathrm{g}} 0.1 \mathrm{~mol} \% \mathrm{CuCl}$ was used.

yield when the polymerization was conducted at $30^{\circ} \mathrm{C}$ for $7 \mathrm{~h}$ (Run 1 in Table 1). At higher polymerization temperature, the polymerization solution is liable to be gel. It is widely accepted that the excess amounts of amine ligands suppresses an unfavorable $\mathrm{C}-\mathrm{C}$ coupling for 2,6-dimethylphenol. ${ }^{1}$ In fact, extra addition of TMEDA for the oxidative coupling polymerization of 2,5-dimethylphenol suppresses gelation as well.

Interestingly, when the amount of the copper catalyst is decreased, a chloroform-insoluble white powder is obtained (Run 8). The white powder is still obtained with $0.1 \mathrm{~mol} \%$ of the catalyst although the yield of the polymer is dramatically decreased. Because the polymer has poor solubility even in dichlorobenzene, a highly regio-regulated polymer would precipitate during the reaction. Therefore, the polymerization might proceed within only precipitated part, in which the catalyst was trapped and condensed compared to the solution, resulting in the polymer with poor yield.

Figure 1 depicts the IR spectra of A) gel, B) chloroformsoluble, and C) chloroform-insoluble polymers. All the spectra show the characteristic absorptions of $\mathrm{C}=\mathrm{C}$ stretching at 1500 and $1392 \mathrm{~cm}^{-1}, \mathrm{C}-\mathrm{O}-\mathrm{C}$ stretching at $1176 \mathrm{~cm}^{-1}, \mathrm{C}-\mathrm{H}$ in-plane bending at 1122 and $1064 \mathrm{~cm}^{-1}$, and out-of-plane bending at 887 and $806 \mathrm{~cm}^{-1}$. In addition to these typical absorptions, small-to-medium absorptions are observed at around 1627, 


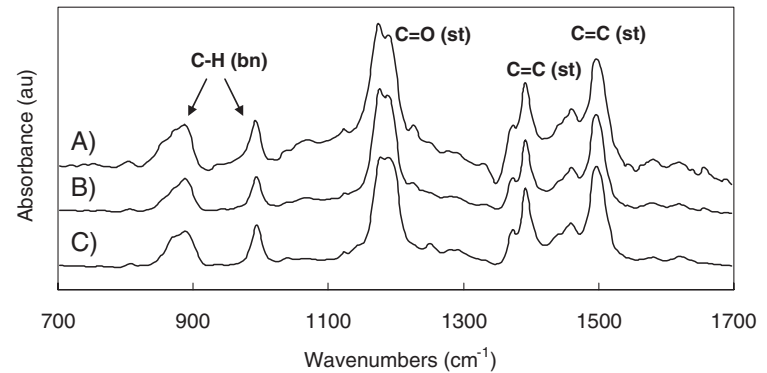

Figure 1. IR spectra of (A) gel, (B) chloroform-soluble polymer, and $(\mathrm{C})$ chloroform-insoluble polymer. The mark * indicates unclear absorptions.

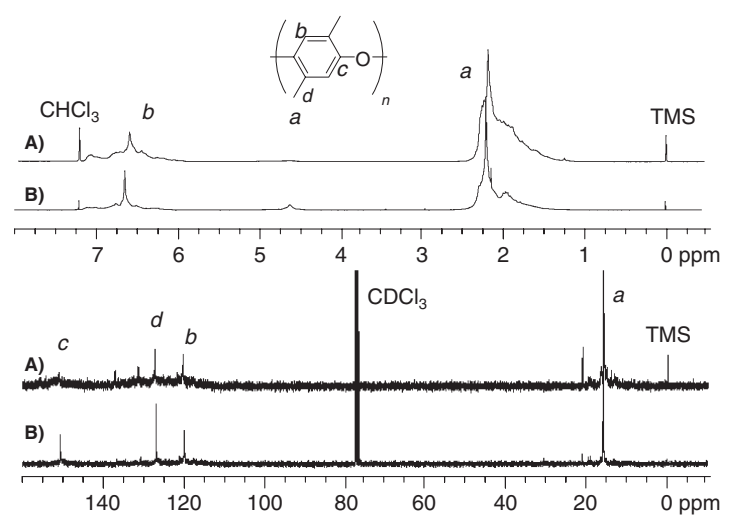

Figure 2. ${ }^{1} \mathrm{H}$ and ${ }^{13} \mathrm{C}$ NMR spectra of the polymers prepared with A) $\mathrm{CuCl}$-pyridine at $40^{\circ} \mathrm{C}$ for $1 \mathrm{~h}$ and $\mathrm{B}$ ) the conditions of Table 1, Run 2.

1461,1245 , and $1064 \mathrm{~cm}^{-1}$ for a gel polymer. The IR spectra of chloroform-soluble and chloroform-insoluble polymers do not show these unclear absorptions, indicating that the both chloroform-soluble and -insoluble polymers have regio-regular structures. In addition the regio-regularity of the chloroform-insoluble polymer, which is hardly dissolved in chloroform, might be higher than the chloroform-soluble polymer.

To characterize the regio-regularity, the ${ }^{1} \mathrm{HNMR}$ and ${ }^{13} \mathrm{CNMR}$ spectra were taken for the polymers prepared with A) $\mathrm{CuCl}$-pyridine at $40{ }^{\circ} \mathrm{C}$ for $1 \mathrm{~h}$ under $\mathrm{O}_{2}$ and $\mathrm{B}$ ) the conditions in Table 1, Run 2 (chloroform-soluble polymer) as shown in Figure 2. Two sharp signals that can be attributed to methyl and aromatic protons were observed at 2.20 and $6.64 \mathrm{ppm}$, respectively, with an integration ratio of 2:6 for polymer B. In the ${ }^{13} \mathrm{CNMR}$ spectrum, signals that can be attributed to the methyl and aromatic carbons were observed at 16.25, 120.51, 127.39 , and $151.23 \mathrm{ppm}$ for polymer B. In contrast, polymer A shows broad and unclear signals as well as those observed in polymer B. These results clearly indicate the satisfactory formation of poly(2,5-dimethyl-1,4-phenylene ether) when the polymerization was conducted with the $\mathrm{CuCl}-\mathrm{TMEDA}$ catalyst.

Figure 3 depicts DSC profiles of A) chloroform-soluble polymer (Table 1, Run 2) and B) chloroform-insoluble polymer (Table 1, Run 9). The chloroform-insoluble polymer shows a

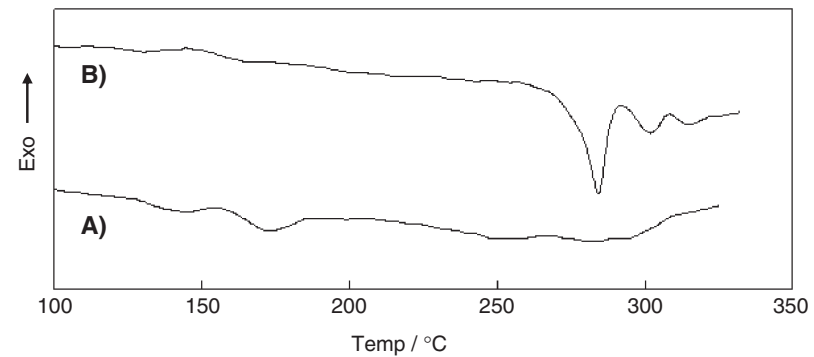

Figure 3. DSC profiles of the polymers obtained by the conditions of A) Run 2, Table 1, and B) Run 9, Table 1.

sharp endothermic peak at $280^{\circ} \mathrm{C}$ along with broad ones due to melting, while no clear peak was observed for the chloroform-soluble sample. The melting point observed for B) is lower than that of the polymer prepared with $\mathrm{CuCl}-2$-phenylpyridine catalyst $\left(320^{\circ} \mathrm{C}\right)$, which might be due to slightly lower regioregularity. This assumption is supported by the lower heat of fusion of $8.6 \mathrm{~J} / \mathrm{g}$ for B). The enthalpy of the melt observed for the polymer prepared with the $\mathrm{CuCl}-2$-phenylpyridine catalyst is 10 to $26 \mathrm{~J} / \mathrm{g}$, which is higher than that of the polymer described above.

Because an aliphatic amine more strongly coordinates with copper ion than an aromatic amine, the bulky state around the copper ion, which is the key for the regio-controlled coupling, is always maintained. Therefore, an aliphatic amine functions as an effective ligand for the regio-controlled oxidative coupling polymerization.

In summary, we demonstrated that the commercially available $\mathrm{CuCl}$-TMEDA complex without additives promoted the regio-controlled polymerization of 2,5-dimethylphenol under mild conditions. When the polymerization was conducted with the catalyst less than $1 \mathrm{~mol} \%$ of the concentration, chloroform-insoluble polymers (higher regio-regularity compared with chloroform soluble polymers) were obtained. This novel approach to control regio-regularity is a powerful tool for the synthesis of phenol polymers, useful for engineering new plastics.

\section{References}

1 A. S. Hay, J. Polym. Sci., Part A: Polym. Chem. 1998, 36, 505.

2 a) Y.-J. Kim, H. Uyama, S. Kobayashi, Macromolecules 2003, 36, 5058. b) H. Higashimura, K. Fujisawa, Y. Moro-oka, M. Kubota, A. Shiga, A. Terahara, H. Uyama, S. Kobayashi, J. Am. Chem. Soc. 1998, 120, 8529. c) S. Kobayashi, H. Higashimura, Prog. Polym. Sci. 2003, 28, 1015. d) H. Higashimura, K. Fujisawa, Y. Moro-oka, S. Namekawa, M. Kubota, A. Shiga, H. Uyama, S. Kobayashi, Macromol. Rapid Commun. 2000, 21, 1121. e) Y. Shibasaki, M. Nakamura, R. Ishimaru, J. N. Kondo, K. Domen, M. Ueda, Macromolecules 2004, 37, 9657. f) H. Higashimura, K. Fujisawa, Y. Moro-oka, M. Kubota, A. Shiga, H. Uyama, S. Kobayashi, Studies in Surface Science and Catalysis, 2003, Vol. 145, p. 423.

3 Y. Shibasaki, Y. Suzuki, M. Ueda, Macromolecules 2007, 40, 5322 . 